\title{
Use of hypnosis as a substitute premedication and adjunct to anesthesia
}

Harsha Shanthanna ${ }^{1 *}$ and Vidya Jeurkar ${ }^{2}$

*Correspondence: harshamd@gmail.com

'Department of Anesthesiology and Pain Medicine, Michael DeGroote School of Medicine, McMaster University, Canada.

${ }^{2}$ Department of Anesthesiology, Dr VM Medical College, Maharashtra, India.

\begin{abstract}
Background: Surgery is associated with significant anxiety and stress in a majority of patients. Most medications used to achieve anxiolysis and sedation are limited by their side effects. 'Non-pharmacological hypnosis' is defined as a subjective state, during which alterations of perception and memory can be elicited by suggestions.

Methods: In this prospective, observational study, hypnosis was used in fifteen patients for a range of surgeries; as a complementary technique to achieve sedation, establishment of intravenous (IV) access, and to decrease the anesthetic dose and postoperative nausea, vomiting.

Results: Hypnosis successfully reduced the anxiety from a range of 45 to 90 (median of 60) to a range of 1 to 20 (median of 10). When calculated and analysed as means, the mean decrease was 56 (95\% CI: 51.81, 60.04) with a p<0.001. Twelve out of fifteen patients had their intravenous access established under hypno-analgesia with no memory of that event. Thirteen patients had successful prevention of nausea, vomiting without antiemetics. Hypnosis also decreased the dose of induction agent in all patients having general anesthesia.

Conclusion: Increasing knowledge and sophistication in anaesthesiology has given a wide spectrum of anesthetic agents and equipments to choose. However, achievement of sedation, anxiolysis and IV access are still areas of challenge which need more human interaction rather than administration of a miracle agent. We aim to demonstrate that hypnosis is well suited for such a purpose and should be utilised, at least in suitable patients.
\end{abstract}

Keywords: Hypnosis, sedation, anxiolysis, intravenous access, hypnoanesthesia, hypnoanalgesia

\section{Introduction}

Hypnosis is defined as state of focussed attention with heightened receptivity for acceptable suggestions [1]. Although hypnotism is known to have been practiced by many people, it was James Braid who popularised its use in anesthesia. With the advent and rapid popularity of nitrous oxide, ether and chloroform, and also thanks to the discredit from the use of hypnosis by stage hypnotists and charlatans, the use of hypnosis in anesthesia dwindled [2]. The regained interest and use of hypnosis in anesthesia practice can be largely attributed to the recognition by British Medical Association (1995) and American Medical Association (1958). Later to that the use of hypnosis has still been sporadic and limited to a few places. It is mostly practiced as a complementary technique, rather than a sole anaesthetic technique. However, there are places where it is used as a sole anesthetic, even for major surgery. The procedure begins with induction, during which time the patient is taken into a trance stage. The depth of trance obtained could be light, medium or deep; and it depends upon both the subject and the hypnotist. For medical use, including sedation and anxiolysis, even light stage is beneficial [3]. Suggestions are delivered to the patient (subject) depending upon the goals of the session. Post-hypnotic suggestions are those which are targeted at physiological and psychological modifications, even after the subject comes out of the trance stage-for example: prevention of nausea and vomiting. We studied the use of hypnosis as a complementary technique to achieve non pharmacological sedation, establishment of intravenous (IV) access, decrease in other anesthetic agents and improved analgesia with lesser side effects.

\section{Methodology}

This observational, prospective case series (study) was done at a well recognised post graduate medical college and hospital in India. Prior approval from the institutional ethics board was obtained. All techniques were done under the supervision of our professor (VJ), coauthor of this article. Dr VJ is an anesthesiologist who is also trained in hypnoanesthesia and has several publications to her credit on the same topic. All patients involved were explained about the technique and a written consent obtained, either from the patient or their parent (in the case of children). We studied the use of hypnosis as a complementary tool to produce anxiolysis, sedation and analgesia for various surgical procedures. Primary objectives were; 1 ) to decrease perioperative anxiety and as a tool for sedation, 2) to establish analgesia and amnesia for IV access. Secondary objectives were; 1) to decrease anesthetic requirements, 2) to prevent nausea and vomiting by hypnosis, along with producing a smoother 

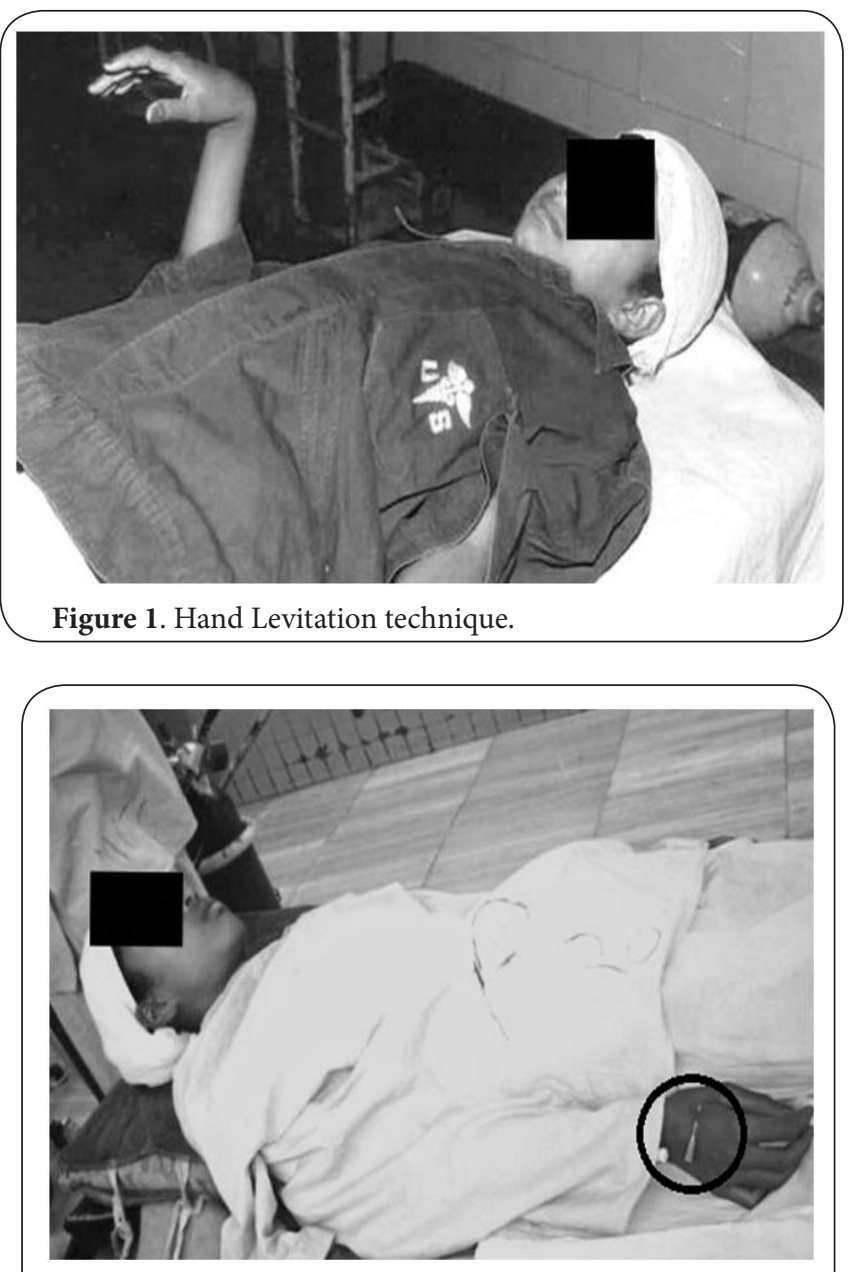

Figure 2. Demonstration of hypnoanalgesia before IV insertion.

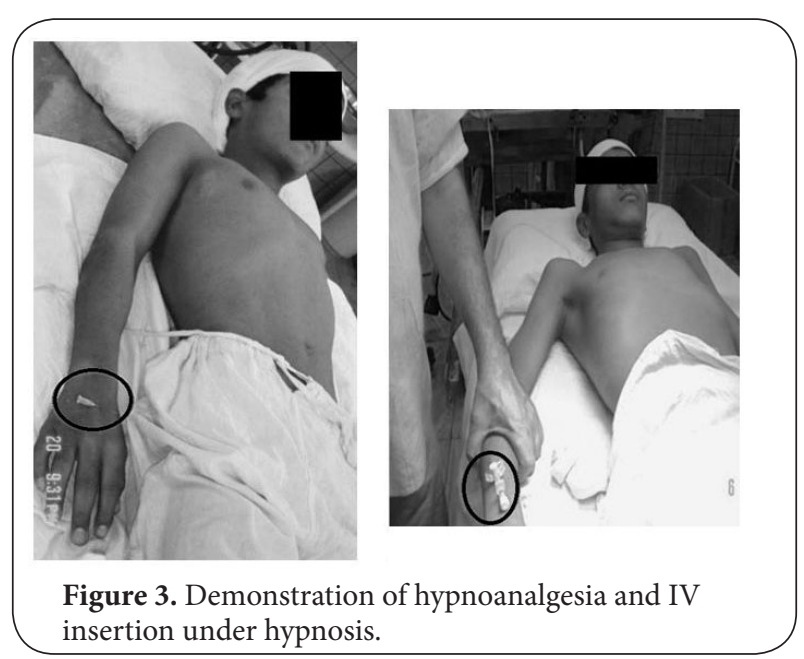

recovery due to posthypnotic suggestions. A total of 15 cases were studied and followed. Inclusion criteria included any surgical procedure necessitating IV access, use of analgesic and sedative medications with or without full anesthesia. Exclusion criteria included patient or parent refusal, cognitive impairment or psychiatric disease which is moderate to severe, patient's inability to comprehend the spoken language. Patients were screened for hypnotic suggestibility by tests such as eyeball set or hand levitation test, done at least a day prior to surgery and appropriate response noted [3]. The level of anxiety was also noted in VAS scale (1-100). Out of 18 cases screened for susceptibility by suggestions and observation, 13 patients were chosen. Two other cases were done on an emergency basis. All selected patients were informed about the visual analogue scale for anxiety (0-100). On the day of surgery, the anxiety scale was again assessed and noted. Hypnosis was induced mostly by verbalization (patient spoken to in the local language-Marathi or Hindi) method, by suggestions and commands aimed at "full body" relaxation; and when a light trance was achieved-noted by regular and relaxed respiratory movements and eye movements, verbalization was done specifically to achieve analgesia of the extremity (glove anesthesia), where an IV access was planned. The suggestions given to achieve analgesia of hands commonly included getting the hand slowly into a bucket full of ice, making it numb and insensate. The suggestions were reinforced by ideomotor and ideosensory responses. Other techniques to deepen the trance included hand levitation technique (Figure 1). In 12 out of 15 cases, IV access was tried under trance. The emergency cases had their IV access established prior to our intervention. In all 12 patients, sufficient analgesia for IV access was demonstrated by observing for response to pin prick (see Figure 2,3). After establishing IV access, patient was assessed for anxiety score, depth of trance and sedation by observation and patient response. Suggestions were administered with respect to the following; 1 ) safe, smoother and easier recovery, 2) effective pain relief, 3) effective prevention of nausea, vomiting and, 4) early discharge and return to activities. After that, sedation or anesthesia was induced appropriate to the surgical procedure. Two minor procedures were done only under hypnosis; and in 2 other high risk patients, minor surgical procedures were performed with only minimal doses of sedatives, apart from hypnosis. The actual procedures and anesthesia used is depicted in the (Table 1). During anesthesia, the dose of induction agents or sedatives administered was noted. Postoperatively, patients were questioned regarding the anxiety levels before going under anesthesia, any memory of intra-operative events, and adequacy of pain relief. Patient was further followed up till discharge for postoperative nausea and vomiting.

\section{Results}

The age of patients varied from 6 years to 68 years. Patient with ASA 1 to 3 were mostly included except a child of 6 years who had severe empyema, and a lady with severe anemia. In all cases, satisfactory level of trance was achieved. Levels of trance achieved are noted in (Table 2). Hypnosis significantly 
Shanthanna et al. Journal of Anesthesiology and Clinical Science 2013, http://www.hoajonline.com/journals/pdf/2049-9752-2-25.pdf

Table 1. List of Surgical Cases in Which Hypnosis Was Utilised.

\begin{tabular}{|c|c|c|c|c|c|c|}
\hline Age & Sex & ASA & Procedures & Anesthesia & $\begin{array}{l}\text { Induction/Sedative } \\
\text { agent }\end{array}$ & $\begin{array}{l}\text { Nausea } \\
\text { Vomiting }\end{array}$ \\
\hline 8 & M & 2 & Tonsillectomy & GA & Thiopentone $2 \mathrm{mg} / \mathrm{kg}$ & No \\
\hline 44 & M & 3 & $\begin{array}{l}\text { Thyroidectomy for Controlled Graves } \\
\text { Disease }\end{array}$ & GA & Thiopentone $2.5 \mathrm{mg} / \mathrm{kg}$ & $\begin{array}{l}1 \text { episode } \\
\text { of vomiting }\end{array}$ \\
\hline 26 & $\mathrm{~F}$ & 1 & Ganglion Excision & $\begin{array}{l}\text { only } \\
\text { HYPNOSIS }\end{array}$ & Nil & No \\
\hline 65 & $\mathrm{~F}$ & 4 & $\begin{array}{l}\text { Dilation Currettage for } \\
\text { postmenopausal bleeding }\end{array}$ & Minimal Sedation & $\begin{array}{l}\text { Midazolam } \\
1 \mathrm{mg}+\text { Pentazocine } \\
6 \mathrm{mg}\end{array}$ & No \\
\hline 60 & M & 3 & Rt Humerus Plating & $\begin{array}{l}\text { Interscalene brachial } \\
\text { plexus block }\end{array}$ & Nil & No \\
\hline 30 & $\mathrm{~F}$ & 1 & Fibroadenoma Excision & GA & Thiopentone $1.5 \mathrm{mg} / \mathrm{kg}$ & No \\
\hline 68 & M & 3 & Inguinal Herniorrhaphy RA & Inguinal Field Block & Nil & No \\
\hline 35 & M & 2 & Laparascopic appendicectomy & GA & Thiopentone $2 \mathrm{mg} / \mathrm{kg}$ & No \\
\hline 42 & $\mathrm{~F}$ & 1 & Laparascopic Cholecystectomy & GA & Thiopentone $2.5 \mathrm{mg} / \mathrm{kg}$ & No \\
\hline 6 & $\mathrm{~F}$ & $4 \mathrm{E}$ & ICD insertion for Severe Empyema & Minimal Sedation & Midazolam $0.5 \mathrm{mg} / \mathrm{kg}$ & $\begin{array}{l}\text { Nausea+, } \\
\text { no } \\
\text { vomiting }\end{array}$ \\
\hline 14 & M & 1 & Ilizarov's Implant removal & only HYPNOSIS & Nil & No \\
\hline 18 & $\mathrm{~F}$ & 2 & Closed Reduction and $\mathrm{K}$ wiring & GA & Thiopentone $2 \mathrm{mg} / \mathrm{kg}$ & No \\
\hline 16 & M & $2 \mathrm{E}$ & Debridement & Ankle block & Nil & No \\
\hline 10 & M & 1 & Suturing of lacerated wound & GA & Thiopentone $2 \mathrm{mg} / \mathrm{kg}$ & No \\
\hline 48 & $\mathrm{~F}$ & 3 & Mastectomy for Ca Breast & GA & Thiopentone $2.5 \mathrm{mg} / \mathrm{kg}$ & No \\
\hline
\end{tabular}

Table 2. Level of Hypnotic Trance Achieved.

\begin{tabular}{ll}
\hline Level of Trance & $\mathbf{n = 1 5}$ \\
\hline Light & 8 \\
Medium & 4 \\
Deep & 3 \\
\hline
\end{tabular}

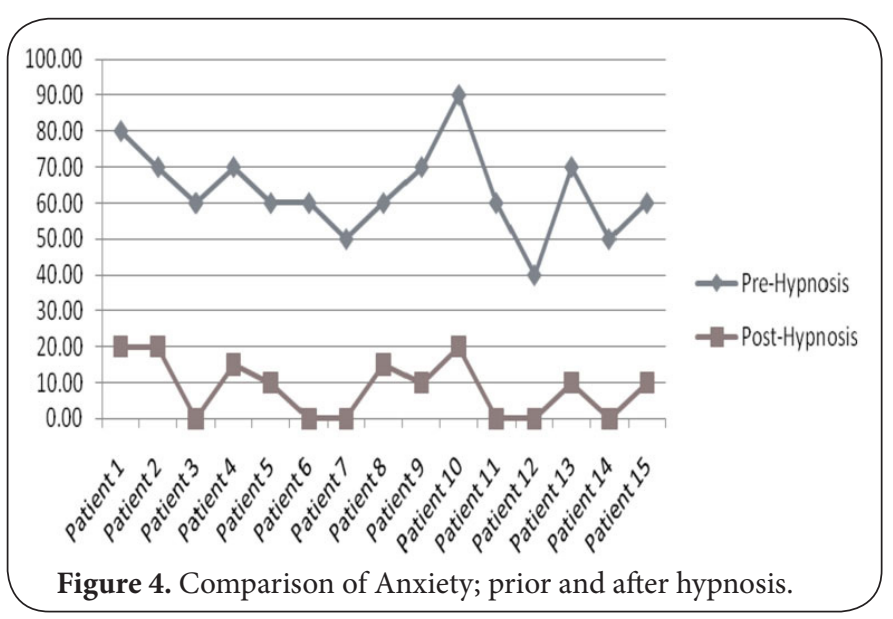

decreased the level of anxiety in all patients, which is depicted in (Figure 4). The level of anxiety prior to hypnosis was in the range of 45 to 90 with a median of 60 (VAS 0-100). Posthypnosis the range of anxiety was 1 to 20 with a median of 10 . When calculated and analysed as means, the mean decrease was
56 with a SD of 11.33 (95\% Cl: 51.81, 60.04). The difference was statistically significant as observed by the $P$ value $<$ 0.001 (paired Student t test). In 12 patients, hypnoanalgesia to IV access was determined by response to pin prick (demonstrated in Figure $\mathbf{2}$ and $\mathbf{3}$ ), along with observation for change in heart rate, and eliciting memory for the event. Ten patients demonstrated complete analgesia with no change in heart rate; however, 2 patients demonstrated an increase in heart rate of less than $20 \%$ from base line with memory of that event despite no response to pin prick. Three of the 15 patients had IV access pre-established for other reasons and could not be tested. In 2 patients in whom we noted deeper level of trance, procedures were done without any further use of sedatives or analgesics (Table 3). The patients were tested for response to pinch from surgical clip in the area and patients were continuously monitored with ASA (American Society of Anesthesiology) recommended monitoring standards and for any necessity of analgesic or anesthetic administration. In 2 other minor surgical procedures, only minimal sedation was used without any anesthetic agents. Both were in high risk patients who underwent the procedures without any complications (Table 4). In all the above 4 patients, complete amnesia to intraoperative events apart from satisfactory sedation and analgesia was achieved. General anesthesia (GA) was used in 8 cases; 5 of them had endotracheal intubation. Hypnosis decreased the dose of IV induction agent (thiopentone sodium) in all cases. The mean dose of induction agent used was $2.12 \mathrm{mg} / \mathrm{kg}$, demonstrating marked decrease in its 
Shanthanna et al. Journal of Anesthesiology and Clinical Science 2013,

http://www.hoajonline.com/journals/pdf/2049-9752-2-25.pdf

doi: $10.7243 / 2049-9752-2-25$

Table 3. List of Cases Performed Only Under Hypnosis.

\begin{tabular}{ll}
\hline Cases Under Only Hypnosis & Systemic Condition \\
\hline Ganglion Excision of flexor tendon Right hand & ASA 2 (hypertension) \\
Ilizarov's implant removal & ASA 1 \\
\hline
\end{tabular}

ASA: American Society of Anesthesiology

Table 4. List of Cases Performed Under Hypnosis and Minimal Sedation.

\begin{tabular}{lll}
\hline Cases & Systemic Disease/Condition & Medications Used \\
\hline $\begin{array}{l}\text { ICD } \\
\text { insertion }\end{array}$ & $\begin{array}{c}\text { ASA 4 } \\
\text { (severe chest infection and empyema) } \\
\text { ASA 4 (IHD with post menopausal bleeding }\end{array}$ & $\begin{array}{l}\text { Midazolam 0.5 mg + } \\
\text { Pentazocine } 3 \mathrm{mg}\end{array}$ \\
D and C & $\begin{array}{l}\text { Midazolam } 1 \mathrm{mg}+ \\
\text { Pentazocine } 9 \mathrm{mg}\end{array}$ \\
\hline
\end{tabular}

ASA: American Soceity of Anesthesiology

ICD: Intercostal Drain

$\mathrm{D}$ and C: Dilation and Currettage

use when compared to the average dose normally used (4-6 $\mathrm{mg} / \mathrm{kg}$ ). In all cases, successful induction was confirmed with eyelash reflex, vocal response and response during intubation. The dose of muscle relaxant used to intubate was as per recommended doses. Since the study was mainly aimed at studying sedation and reduction of anxiety through hypnosis, the reduction in doses of other intraoperative agents has not been recorded. All patients showed complete amnesia and no recall of intraoperative events when assessed postoperatively. 13 out of 15 cases showed successful prevention of nausea, vomiting by hypnosis while the 2 remaining patients had 1 episode of severe nausea treated by antiemetic.

\section{Discussion}

Our study demonstrates that non-pharmacological hypnosis is a very effective tool to decrease the anxiety associated with surgical procedures. In our study, all patients showed a decrease in their anxiety varying from $50 \%$ to complete relief. VAS scale has been previously shown to be a useful and valid method for measuring preoperative anxiety, and correlated well with (STAI) Speilberger State - Trait Anxiety Inventory [4]. The reduction in anxiety was clinically and statistically very significant. Clinically meaningful reduction of anxiety does not necessitate deeper level of trance $[1,3]$. Eight out of 15 patients were observed to have only lighter level of trance. Surgical period is associated with significant distress, anxiety and stress in at least $70 \%$ of patients [5]. Anxiety apart from causing visible distress to the patient puts him at risk of other adverse events [4]. It is more relevant in a high risk surgical patient where there is a decrease of systemic reserve which may necessitate decrease in anesthetic doses. Most common factors causing anxiety include; fear of unknown, fear of feeling ill, fear of waking up during surgery, fear of surgical pain. In paediatric and young patients, fear of unknown dominates. Hypnosis has been successfully used to decrease anxiety in various surgeries [6] and invasive medical procedures [7]. Two other recent studies have shown the usefulness of hypnosis in decreasing preoperative anxiety. Saadat et al., studied the use of hypnosis specifically for reduction of anxiety in ambulatory procedures and showed that hypnosis was much more effective than attention-control, or the control group [6]. Calipel et al., compared the use of hypnosis with midazolam in children [8] and, they observed statistically significant decrease $(p<0.05)$ in anxiety at mask placement. One of the other primary objectives of our study was to achieve a depth enough to create hypnoanalgesia, sufficient to introduce a 20G IV canula. Out of 12 patients, 10 patients felt no pain and did not remember the event. The other two did not feel the pain but remembered the event. Achieving IV access can often be very challenging, especially in children. A significant proportion of children undergoing peripheral venipuncture suffer from moderate to severe pain and elevated levels of pre-procedural and procedural distress. In fact many children report that this could be on par with the surgical pain [9]. Disappointingly sometimes, prior attempt at decrease in anxiety may be nullified by the increasing anxiety and stress caused by attempts at IV access. As demonstrated, our attempt at insertion happened after achieving sufficient depth to produce relaxation and analgesia which was then tested by a hypodermic needle, after which the canula was inserted. No previous studies have tested the utility of hypnosis in this regard. We feel hypnosis is particularly useful in this regard with extremely anxious and pediatric patients. Hypnoanalgesia, usually limited to a particular region of the body, can be effected by suitable hypnotic commands and suggestions. Complete analgesia, sufficient for the entire surgical procedure is difficult and quite unpredictable. However, hypnosis has been used as the sole anesthetic $[10,11]$. Even in experienced hands, considering only less than $10 \%$ of the general population can be hypnotised this way, $[3,4,10]$ it may not be meaningful to attempt a surgery under only hypnosis except in unusual circumstances. Hypnosis has been effectively used along with sedation and local anesthesia for various regional procedures [12-14]. Although we did not plan to perform any procedure under only hypnosis, a total of 4 procedures were done without necessitating the use of any general anesthetic. Two procedures were done with only local anesthesia infiltration facilitated by hypnosis (Table 3). Two other procedures, in high risk patients, were done with the use of minimal sedation (Table 4). The demands of conscious sedation often include a high risk patient who cannot tolerate a GA $[6,10]$. Hypnosis helps by anxiolysis, decreasing the requirements of other medications and even avoiding GA in suitable patients. More significantly hypnosis achieves a state of mind which prevents sudden agitation and movement, which could be potentially dangerous in ophthalmic and other surgeries [15]. Three procedures were done with the use of regional analgesia supplemented by 
hypnosedation. None of them required any additional IV sedatives or anesthetic agents. All the 8 patients of general anesthesia had smooth induction. The average (mean) dose of thiopentone was $2.12 \mathrm{mg} / \mathrm{kg}(1.5-2.5 \mathrm{mg} / \mathrm{kg})$, demonstrating a decrease of $>50 \%$ when compared to the normal range of 4-6 mg/kg. Montgomery et al., demonstrated decrease use of propofol in the hypnosis group; a mean difference of 32.63 (95\% Cl: $3.95,61.30)$ compared to control group in breast surgery patients [16]. Decrease of anesthetic medications is advantageous by way of decreasing the potential side effects. Postoperative nausea and vomiting (PONV) is said to be the "little big problem". Irrespective of the antiemetic therapy and prophylaxis, PONV has an incidence of $30-50 \%$ after GA [17]. It prolongs recovery room stay, sometimes necessitates admission and increases the overall cost. In our study, only 2 patients required pharmacological therapy for PONV. Previous studies have shown that hypnosis is effective for prevention of nausea and vomiting $[1,2,18,19]$. All 15 patients in our study also had smooth postoperative course and reported complete amnesia for intra-operative events.

We conclude that hypnosis is an effective non-pharmacological tool for reduction of preoperative anxiety and sedation. The phenomenon of hypnoanalgesia can be utilised for IV access and other minor medical procedures, which significantly reduces the overall distress and improves patient recovery.

\section{Competing interests}

The authors declare that they have no competing interests.

Authors' contributions

Harsha Shanthanna: Primary Investigator and Author.

Vidya Jeurkar: Research Supervision and Co-author.

Acknowledgement

We acknowledge the support of the staff and patients at

DrV M Medical College and Hospital, Solapur, India.

\section{Publication history}

Editor: Ahmet Eroglu, Karadeniz Technical University, Turkey.

Received: 24-May-2013 Revised: 09-Jun-2013

Accepted: 13-Jun-2013 Published: 24-Jun-2013

\section{References}

1. Stewart JH: Hypnosis in contemporary medicine. Mayo Clin Proc 2005, 80:511-24. | Article | PubMed

2. Wobst $\mathrm{AH}$ : Hypnosis and surgery: past, present, and future. Anesth Analg 2007, 104:1199-208. I Article I PubMed

3. Kroger WS. and Philadelphia J. B: Lippincott Company. Chapter 8 and 9, 2nd Edition. Clinical and Experimental Hypnosis In Medicine, Dentistry, and Psychology, 2nd ed. 1997. I Book

4. Kindler CH, Harms C, Amsler F, Ihde-Scholl T and Scheidegger D: The visual analog scale allows effective measurement of preoperative anxiety and detection of patients' anesthetic concerns. Anesth Analg 2000, 90:706-12. | Article | PubMed

5. Ramsay MA: A survey of pre-operative fear. Anaesthesia 1972, 27:396402. | Article | PubMed

6. Saadat H, Drummond-Lewis J, Maranets I, Kaplan D, Saadat A, Wang SM and Kain ZN: Hypnosis reduces preoperative anxiety in adult patients. Anesth Analg 2006, 102:1394-6. | Article I PubMed
7. Lang EV, Benotsch EG, Fick LJ, Lutgendorf S, Berbaum ML, Berbaum $\mathrm{KS}$, Logan $\mathrm{H}$ and Spiegel D: Adjunctive non-pharmacological analgesia for invasive medical procedures: a randomised trial. Lancet 2000, 355:1486-90. | Article | PubMed

8. Calipel S, Lucas-Polomeni MM, Wodey E and Ecoffey C: Premedication in children: hypnosis versus midazolam. Paediatr Anaesth 2005, 15:275-81. | Article | PubMed

9. Zempsky WT: Optimizing the management of peripheral venous access pain in children: evidence, impact, and implementation. Pediatrics 2008, 122 Suppl 3:S121-4. | Article | PubMed

10. Morris DM, Nathan RG, Goebel RA and Blass NH: Hypnoanesthesia in the morbidly obese. JAMA 1985, 253:3292-4. | Article | PubMed

11. Defechereux T, Meurisse M, Hamoir E, Gollogly L, Joris J and Faymonville ME: Hypnoanesthesia for endocrine cervical surgery: a statement of practice. J Altern Complement Med 1999, 5:509-20. I Article I PubMed

12. Montgomery GH, David D, Winkel G, Silverstein JH and Bovbjerg DH: The effectiveness of adjunctive hypnosis with surgical patients: a meta-analysis. Anesth Analg 2002, 94:1639-45. I Article I PubMed

13. Sefiani T, Uscain M, Sany JL, Grousseau D, Marchand P, Villate $D$ and Vincent JL: [Laparoscopy under local anaesthesia and hypnoanaesthesia about $\mathbf{3 5}$ cholecystectomies and 15 inguinal hernia repair]. Ann Fr Anesth Reanim 2004, 23:1093-101. I Article I PubMed

14. Faymonville ME, Fissette J, Mambourg PH, Roediger L, Joris J and Lamy $M$ : Hypnosis as adjunct therapy in conscious sedation for plastic surgery. Reg Anesth 1995, 20:145-51. | Article I PubMed

15. Lewenstein LN, Iwamoto $\mathrm{K}$ and Schwartz $\mathrm{H}$ : Hypnosis in high risk ophthalmic surgery. Ophthalmic Surg 1981, 12:39-41. I PubMed

16. Montgomery GH, Bovbjerg DH, Schnur JB, David D, Goldfarb A, Weltz CR, Schechter C, Graff-Zivin J, Tatrow K, Price DD and Silverstein JH: A randomized clinical trial of a brief hypnosis intervention to control side effects in breast surgery patients. J Natl Cancer Inst 2007, 99:1304-12. | Article | PubMed

17. Islam S and Jain PN: Post-operative nausea and vomiting (ponv): a review article. Indian J. Anaesth 2004, 48:253-258. I Pdf

18. Enqvist B, Bjorklund C, Engman M and Jakobsson J: Preoperative hypnosis reduces postoperative vomiting after surgery of the breasts. A prospective, randomized and blinded study. Acta Anaesthesiol Scand 1997, 41:1028-32. | Article | PubMed

19. Williams AR, Hind M, Sweeney BP and Fisher R: The incidence and severity of postoperative nausea and vomiting in patients exposed to positive intra-operative suggestions. Anaesthesia 1994, 49:340-2. | Article I PubMed

\section{Citation:}

Shanthanna $\mathrm{H}$ and Jeurkar V: Use of hypnosis as a substitute premedication and adjunct to anesthesia. J Anesthesiol Clin Sci 2013, 2:25. http://dx.doi.org/10.7243/2049-9752-2-25 